\title{
Mechanical properties of friction-stir-welded polyamide sheets
}

\author{
Imad M. Husain', Raed K. Salim", Taher Azdast ${ }^{2}$, Soran Hasanifard ${ }^{3}$, Sajjad M. Shishavan² and Richard Eungkee Lee ${ }^{4}$
}

\begin{abstract}
Background: In this study, the effect of processing parameters on the mechanical properties of friction-stir-welded polyamide (nylon 66) sheets is investigated.

Methods: Commercial polyamide sheets with the dimension of $250 \times 150 \times 8 \mathrm{~mm}$ are used in experimentations. The processing parameters considered in the welding include: rotational speeds in five levels and traverse speeds in three levels. Tensile and impact tests are performed in order to evaluate mechanical behavior of welded sheets. Full-factorial design of experiments and also analysis of variance was performed in present study.

Results: Results show that when rotational speed increases, weld strength first increases and then decreases. In other words, there is an optimum rotational speed in which the welded samples could obtain the highest tensile Strength. Regarding the traverse speed, weld strength decreases with increasing of the traverse speed.

Conclusions: Obtained results show a significant relationship between considered properties and processing parameters through an analysis of variance (ANOVA) study.
\end{abstract}

Keyword: Friction; Stir; Welding; Polyamide; Mechanical properties

\section{Background}

The real plastics revolution in automotive industry began in 1950 when thermoplastics made their debut, starting with acrylonitrile butadiene styrene (ABS) and going on to polyamide (PA), polyoxymethylene (POM), and polycarbonate $(\mathrm{PC})$ together with introduction of alloys and blends of various polymers. The ongoing development of advanced and high-performance polymers has dramatically increased their usage. Originally, plastics were specified because they offered good mechanical properties combined with excellent appearance, including the possibility of self-coloring. The application of plastic components in the automotive industry has been increasing over the last decades. Nowadays, the plastics are used mainly to make cars more energy efficient by reducing weight, together with providing durability, corrosion resistance, toughness, design flexibility, resiliency, and high performance at low cost (Szeteiova 2011). Friction stir welding is a new solid-state joining technique, which was originally developed and successfully applied for aluminum alloys. However, recently, attempts have been made to adapt friction stir welding technology to the joining of thermoplastic materials. In this solid-state

\footnotetext{
* Correspondence: t.azdast@urmia.ac.ir

${ }^{2}$ Mechanical Engineering Department, Faculty of Engineering, Urmia

University, Urmia, Iran

Full list of author information is available at the end of the article
}

joining process which welds the materials, the characteristics and properties must remain unchanged as far as possible (Shaikh et al. 2014). Many researchers investigated and formulated friction stir welding process which has produced structural joints superior to conventional arc welds in aluminum, steel, nickel, copper, and titanium alloys. Research and development efforts over the last decade have resulted in improvements in friction stir welding and the spin-off of a series of related technologies.

Sorensen et al. (2001) at Brigham Young University (BYU) studied the mechanical properties of the thermoplastics with friction stir welding (FSW) method using a hot shoe. In this study, they used non-threaded tools first and found that pin without thread causes a lot of tension to the device and a reduction in preserved material in the weld area. They concluded that increasing rotational speed and decreasing travel speed have positive effects on the weld strength.

Strand et al. (2003) at BYU, in another study in 2003, investigated the influence of parameters on flexural strength, tensile strength, and microstructure of the weld. Hot shoe was also used in this study. Experimental results showed that lower speed of travel and higher shoe temperature will lead to strength and better microstructure.

\section{Springer}

(c) 2015 M. Husain et al. This is an Open Access article distributed under the terms of the Creative Commons Attribution License (http://creativecommons.org/licenses/by/4.0), which permits unrestricted use, distribution, and reproduction in any medium provided the original work is properly credited. 
Saeedy and Besharatigivi (2010) have studied the feasibility of friction stir welding on medium density polyethylene blanks. The optimum welding condition has been determined. They have demonstrated that rotation speed and tool tilt angle have key roles in the seam elongation and strength, respectively. By applying this method of welding on polyethylene blanks, about $70 \%$ of the base material strength is achieved.

Also, in other research, Saeedy and Besharati Givi (2011) studied the effect of varying process parameters (rotational speed, welding speed, and attack angle) on the weld quality of polyethylene sheets. A strength value of $75 \%$ of that of the base material was achieved in their experimentation.

Aydin (2014) investigated the weld ability of polyethylene via friction stir welding method. In this study, three different heating processes were used. Welding processes are performed at room temperature, welding preheated plate samples at 50 and $80{ }^{\circ} \mathrm{C}$ with metal molding. A tensile strength of $72 \%$ was achieved in non-preheated welds whereas tensile strength of parent material was achieved approximately at an optimum value of $89 \%$ by pre-heating at $50{ }^{\circ} \mathrm{C}$.

Anna Squeo et al. (2009) performed friction stir welding of 3-mm-thick polyethylene sheets with a cylindrical steel pin having two different pin diameters. Authors has concluded that even if process optimization is required, the final performances of the joints are sufficient to assess that friction stir welding of polyethylene may be a valid alternative to conventional joining technologies.

Arici and Selale (2007) investigates the effect of the tool tilt angle on friction stir welding of polyethylene. They showed that in welded samples, tensile strength decreases with increasing tool tilt angle. They also reveal that when tool tilt angle increases, the thickness of the welding zone decreases which in turn affects the tensile strength.

Payganeh et al. (2011) used friction stir welding for butt joining of polypropylene composite plates having $30 \mathrm{wt} \%$ glass fibers. The results indicated that tool pin geometry had a significant influence on weld quality, and the effects of rotational speed and tilt angle on weld appearance and strength were more than that of traverse speed.

Mendes et al. (2014) in their research work studied the effect of axial force, rotational and traverse speeds, the tool temperature on the morphology, weld quality, tensile strength, and tensile strain of friction-stir-welded acrylonitrile butadiene styrene sheets using a robotic system and a stationary shoulder tool developed to this purpose. They found that high axial force promotes the squeeze of the molten polymeric material, preventing introduction of air into the weld and helps cooling of the weld, avoiding shrinkage, and voids formation. Also, they observed that high axial force improves tensile strength and strain of welds. In addition, it is reported that the rotational speed is primarily responsible for heat generation, promoting adequate plasticizing, and mixing the polymer, and high tool rotational speed improves tensile strength and strain of welds.

Kumar et al. (2012) in their experimental research work studied the welding force of friction stir welding of AA5083. Their results show that tool rotational speed, welding speed, and tool shoulder diameter are the most significant parameters affecting axial force. They also showed that longitudinal force is significantly affected by welding speed and probe diameter.

In present research work, friction-stir-welded butt joints of polyamide sheets are obtained using a cylindrical tool

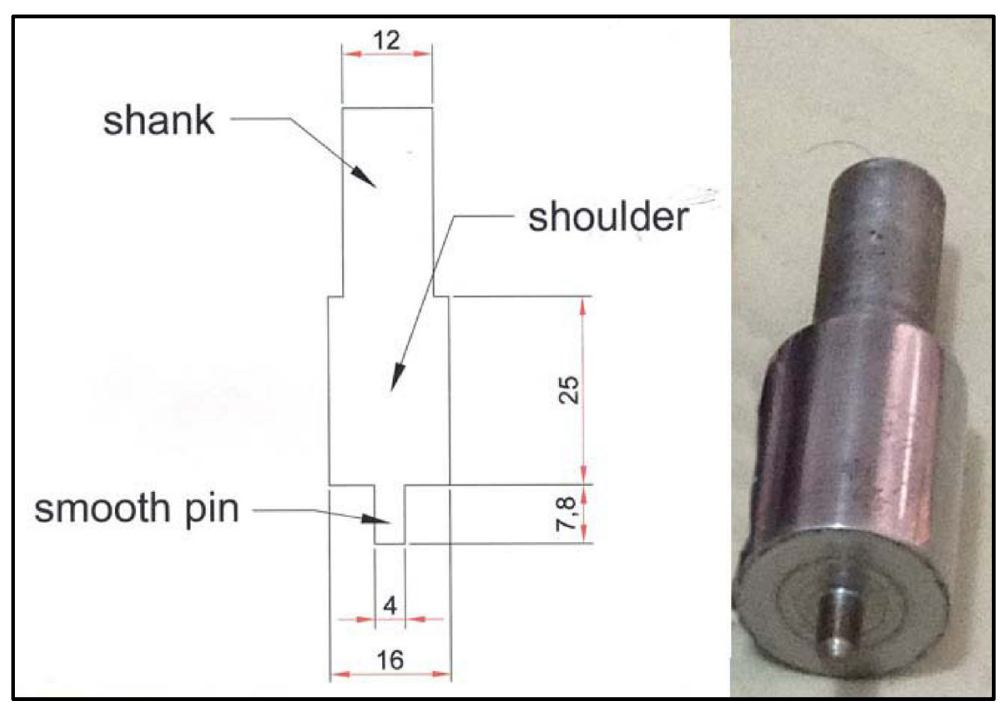

Fig. 1 FSW tool of the present research 
Table 1 Levels of selected parameters in present study

\begin{tabular}{llllll}
\hline Parameter & Level & & & \\
\cline { 2 - 6 } & 1 & 2 & 3 & 4 & 5 \\
\hline Rotational speed $(\mathrm{RPM})$ & 780 & 994 & 1255 & 1570 & 2000 \\
Traverse speed $\left(\mathrm{mm} / \mathrm{m}^{2}\right)$ & 27 & 42 & 62 & $\ldots$ & $\ldots$ \\
\hline
\end{tabular}

in various welding conditions. The aim of the study is to investigate the effect of friction stir welding parameters (rotational and traverse speeds) on the mechanical properties of polyamide sheets in order to obtain the optimum condition that leads to a weld with the highest quality.

\section{Methods}

\section{Materials and tool design}

In the present study, the commercial polyamide sheets (nylon 66) with $8 \mathrm{~mm}$ thickness are utilized to cut in specimens with the dimensions of $150 \times 250 \mathrm{~mm}$ in order to use for the butt joint friction stir welding. Base material of this study has a tensile strength of $15.57 \mathrm{MPa}$, impact strength of $36.636 \mathrm{~kJ} / \mathrm{m}^{2}$, and melting point of $265.8{ }^{\circ} \mathrm{C}$. Friction stir welding of specimens is performed using a specially designed clamping fixture which is mounted on a vertical milling machine. A welding tool made of mild steel with nominal pin and shoulder diameter of 4 and $16 \mathrm{~mm}$, respectively, and also pin length of $7.8 \mathrm{~mm}$ is used in the experimentations. Figure 1 shows the dimension of the used tool of the present research.

\section{Process preparation}

Rotational speed of the pin and traverse speed of the tool along the weld line are selected as the processing parameters. From the preliminary experimental results, the rotational speed is selected $(780,994,1255,1570$, and $2000 \mathrm{rpm}$ ) and traverse speed is selected (27, 42, and $62 \mathrm{~mm} / \mathrm{min}$ ). Selected processing parameters and different levels of each parameter are presented in Table 1. In order to determine the mechanical properties, the welded specimens are examined with tensile and impact test machines. General full factorial design of experiments (DOE) is applied to explore effects of operating parameters. Also, the analysis of variance (ANOVA) study is performed in order to determine the significance of process parameters and the relationship between them and the mechanical properties of the welds.

At the start, the FSW tool is plunged into the sheets until it touched the shoulder surface. After few seconds as the dwelling time of preheating and softening of the material, the tool starts to moves along the weld line. Since the tool is removed when it reached to the end of the line, a hole is created at the end of the joint interface (Panneerselvam and Lennin 2014).

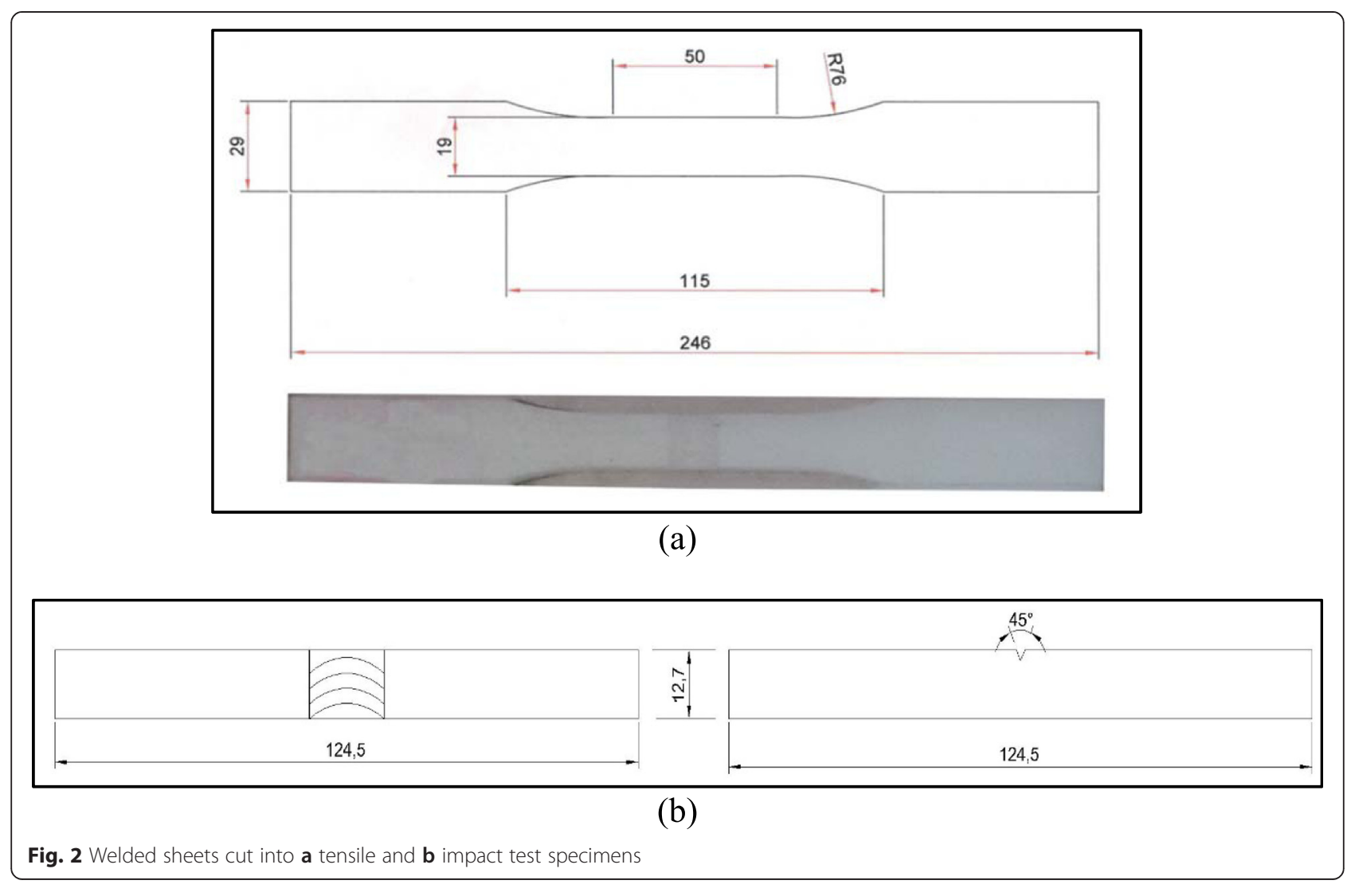




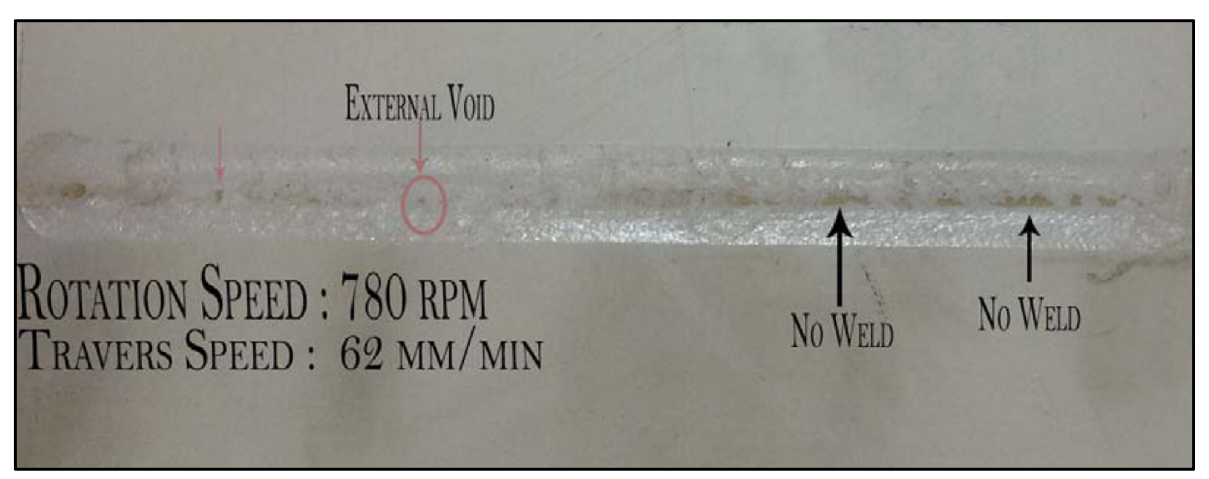

Fig. $3 \mathrm{~A}$ poor and unacceptable weld at very low rotational speed and very high traverse speed

Since the tool rapidly cools in the air and no chips or flashes are produced in the process, there is no need to apply cooling or cleaning procedure. The specimens of tensile and impact tests are cut from the middle part of the welded plates. Also, the cutting direction is perpendicular to the welding direction (Fig. 2). These specimens are cut using a CNC milling machine to a standard size according to American Society for Testing and Materials (ASTM) D638-10 of tensile test (International 2010) and ASTM D6110-10 of impact test (International 2010). Tensile tests are conducted using a Zwick machine with the cross head speed of $5 \mathrm{~mm} / \mathrm{min}$. Also, impact tests are conducted using a SBN impact machine with a head of pendulum weight of $2.036 \mathrm{~kg}$ and arm distance of $39.48 \mathrm{~cm}$.

\section{Result and discussion}

In the experimental procedure, it is found that rotational speeds smaller than $780 \mathrm{rpm}$ produced low frictional heat and inadequate material mixing and therefore, results in welds with a very low mechanical strength. These welded specimens could be easily fractured by hands. Also, it was found that for traverse speed larger than $62 \mathrm{~mm} / \mathrm{min}$, weld line area is full of deformation and external voids leading to weld with poor quality. On the other hand, the limitation of the vertical milling machine restricts using rotational speed larger than $2000 \mathrm{rpm}$ and traverse speed smaller than $27 \mathrm{~mm} / \mathrm{min}$. As an example, Fig. 3 shows a very poor joint of a welded specimen with the rotational speed of $780 \mathrm{rpm}$ and traverse speed of $27 \mathrm{~mm} / \mathrm{min}$.

Table 2 Mechanical properties of welded specimens

\begin{tabular}{|c|c|c|c|c|c|c|}
\hline Trial & Rotational speed (rpm) & $\begin{array}{l}\text { Traverse speed } \\
(\mathrm{mm} / \mathrm{min})\end{array}$ & Tensile strength $(\mathrm{MPa})$ & $\begin{array}{l}\text { Relative tensile } \\
\text { strength (\%) }\end{array}$ & Impact strength $\left(\mathrm{kJ} / \mathrm{m}^{2}\right)$ & $\begin{array}{l}\text { Relative impact } \\
\text { strength (\%) }\end{array}$ \\
\hline 1 & 780 & 27 & 4.78 & 30.70 & 6.26 & 17.08 \\
\hline 2 & 780 & 42 & 1.90 & 12.20 & 3.51 & 9.58 \\
\hline 3 & 780 & 62 & 1.08 & 6.94 & 2.11 & 5.76 \\
\hline 4 & 994 & 27 & 6.93 & 44.51 & 8.32 & 22.71 \\
\hline 5 & 994 & 42 & 3.23 & 20.75 & 6.52 & 17.79 \\
\hline 6 & 994 & 62 & 1.75 & 11.24 & 3.85 & 10.51 \\
\hline 7 & 1255 & 27 & 8.38 & 53.82 & 8.61 & 23.50 \\
\hline 8 & 1255 & 42 & 5.88 & 37.76 & 10.19 & 27.81 \\
\hline 9 & 1255 & 62 & 2.89 & 18.56 & 5.89 & 16.07 \\
\hline 10 & 1570 & 27 & 6.57 & 42.20 & 9.54 & 26.04 \\
\hline 11 & 1570 & 42 & 8.51 & 54.66 & 10.80 & 29.48 \\
\hline 12 & 1570 & 62 & 5.93 & 38.09 & 6.81 & 18.59 \\
\hline 13 & 2000 & 27 & 4.71 & 30.25 & 7.70 & 21.01 \\
\hline 14 & 2000 & 42 & 7.25 & 46.56 & 8.91 & 24.32 \\
\hline 15 & 2000 & 62 & 3.22 & 20.68 & 7.09 & 19.35 \\
\hline Base material & $\ldots$ & $\ldots$ & 15.57 & 100 & 36.64 & 100 \\
\hline
\end{tabular}




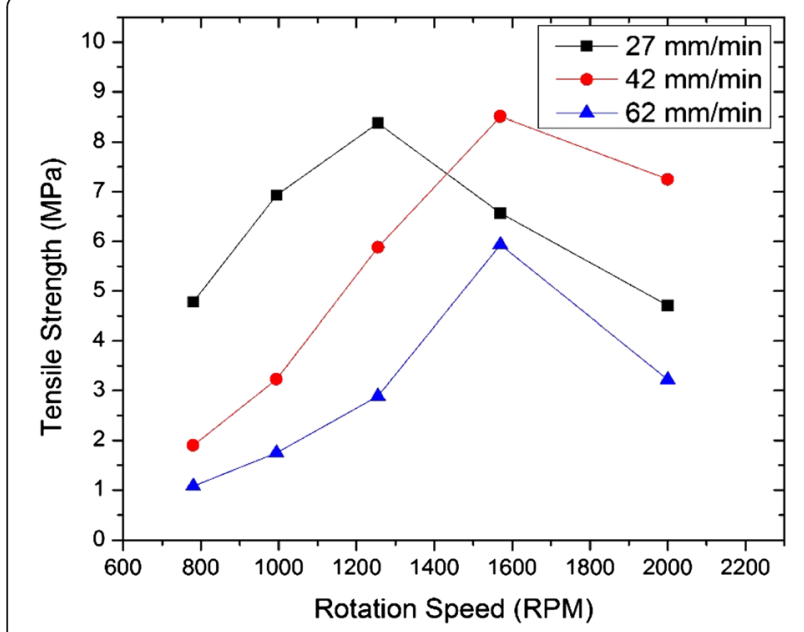

Fig. 4 Tensile strength results of the welded samples

Experimental works of this research are followed by tension and impact tests. Results of tensile and impact strengths and also relative tensile and impact strengths of different specimens are presented in Table 2.

\section{Effect of processing parameters on tensile strength}

Figure 4 shows the results of tensile tests. As the figure shows, when rotational speed increases, the tensile strength first increases and then decreases. In other words, in all transverse speed of the experimentations, there is an optimum rotational speed in which the welded specimens could obtain the highest tensile strength. Also, it is concluded from the figure that as the traverse speed increases, this optimum rotational speed also will be increased. It means that when traverse speed increases, the produced frictional stir heat will be decreased because of the faster movement of the tool. Therefore, in order to compensate for the lost heat, higher rotational speed is needed. Generally, low rotational speeds lead to insufficient flow of material in the weld zone and lack of fusion between the weld and base material. While the stirring of the pin increases with the tool rotational speed, frictional heat also will be increased and consequently better welds will be obtained in terms of mechanical properties (Arici and Sinmaz 2005). However, when the rotational speed goes to the values of rotational speed higher than $1570 \mathrm{rpm}$, the materials are separated by pin and a weak weld will be observed. Regarding traverse speed of the tool, it should be also mentioned that if the traverse speed increases, pouring of the melt material out of the welding area will occur because of the high tangential force exerted on the material. In a high traverse speed, high value of temperature also could not be created. Therefore, poor mixing of the melted material will lead to a weld with poor quality (Bagheri et al. 2013; Hoseinpour Dashatan et al. 2013).

Another important result that could be obtained from Table 2 is the fact that the maximum relative tensile strength of the welded samples is about $54.66 \%$ of the base material that occurred in a specimen welded with rotational speed of $1570 \mathrm{rpm}$ and traverse speed of $42 \mathrm{~mm} /$ min. Also, the minimum strength (about $6.94 \%$ of the base material) occurred in a sample welded with rotational speed of $780 \mathrm{rpm}$ and traverse speed of $62 \mathrm{~mm} / \mathrm{min}$.

Another way to show the effect of processing parameters on the mechanical properties of welded samples is the main effects plot obtained from DOE for tensile strength. Figure 5 is the main effect plot of rotational and traverse speeds for tensile strength. As Fig. 5 shows, tensile strength increases with increasing the rotational speed to $1570 \mathrm{rpm}$, and then a reduction in tensile strength appears on the results. It means that welding with an excessive rotational speed (i.e., larger than $1570 \mathrm{rpm}$ ) will lose more particles from the base material which leads to decrease in thickness. In addition, with excessive rotational speed, the base material will burn. This put the weld in an uncontrolled situation.

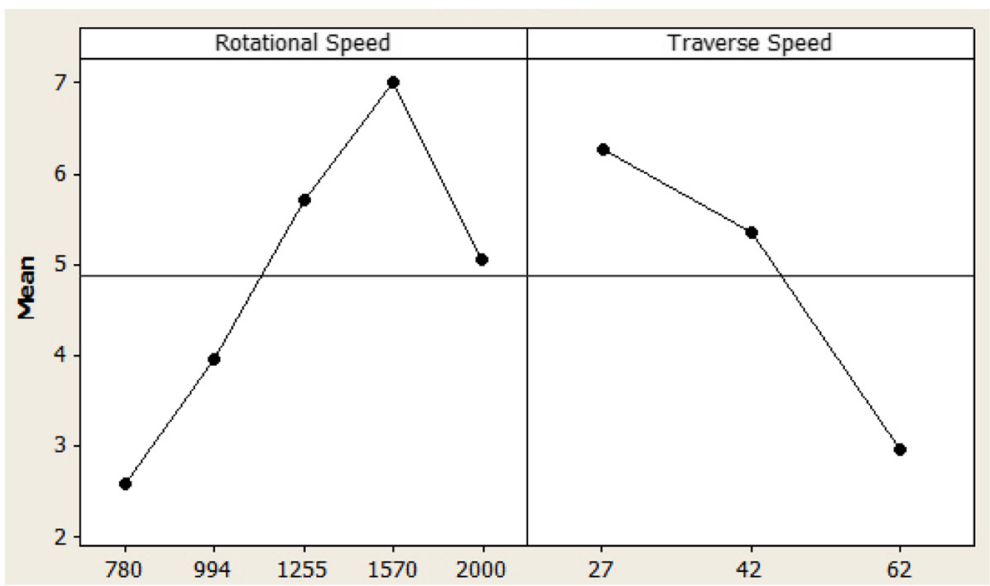

Fig. 5 Main effects of rotational speed on tensile strength 
Table 3 ANOVA table of tensile strength

\begin{tabular}{lccccccc}
\hline Source & DOF & SS & MS & $F_{\text {exp }}$ & $F_{0.05}$ & $P$ & \\
\hline Rotational speed & 4 & 33.983 & 8.496 & 3.43 & 3.84 & 0.065 & Percent effect \\
Traverse speed & 2 & 29.001 & 14.501 & 5.86 & 4.46 & 0.027 & 41.04 \\
Error & 8 & 19.813 & 2.477 & $\ldots$ & $\ldots$ & $\ldots$ & $\ldots$ \\
Total & 14 & 82.797 & $\ldots$ & $\ldots$ & $\ldots$ & $\ldots$ & $\ldots$ \\
\hline
\end{tabular}

Also, as Fig. 5 depicts, welding with higher traverse speed reduces the tensile strength. This could be because of the fact that in higher traverse speed, faster movement of tool leads to poor mixing of the material. In other words, welding with smaller traverse speed allows the two sheets to get enough time for mixing and homogenization. Therefore, weld line deflection and deformation in samples with higher traverse speed lead to poor material mixing and consequently weak tensile strength.

The ANOVA method measures the effect of input variables (i.e., processing parameters of friction stir welding process) on response variables (i.e., tensile and impact strengths of welded joints) through the relationship between these two families of variables. ANOVA method also defines which welding parameters highly affect the quality feature statistically (Mustafa et al. 2011). The Fisher test is used to assess the degree of significance in these relationships. The ANOVA results of tensile strength of the welded specimens of the present study are shown in Table 3. As results show, $P$ value of the rotational speed (0.065) is a little bit bigger than 0.05. It means that rotational speed does not statistically have significant effect on tensile strength at the $95 \%$ level of confidence. However, there is a significant effect on tensile strength for traverse speed due to the small $P$ value of 0.027 . Also, $F$-value of rotational speed obtained from experimental results (i.e., 3.43) is a little bit lower than the statistical calculation of $F$-value (i.e., 3.84). This also shows that rotational speed is an effective parameter on tensile strength of specimens. Similarly, since obtained $F$-values of traverse speed from experimental results (i.e., 5.86) are bigger than concluded $F$-value from statistical calculation (i.e., 4.46), traverse speed is an effective parameter on tensile strength of welded specimens. Results also depict that rotational speed with the percent effect value of 41.04 is the most effective parameter on the tensile strength of welded specimens (Rezgui et al. 2010).

\section{Effect of processing parameters on impact strength}

To ensure and support the analysis of mechanical properties, impact tensile strength tests were inspected to all welding specimens. Results of the impact test for welded polyamide samples of this research are presented in Table 2, too. Figure 6 also shows the results of impact strength for welded polyamide samples. As Fig. 6 displays, impact strength of the welded samples increases if the rotational speed of the tool increases to $1570 \mathrm{rpm}$. Further increase of rotational speed to $2000 \mathrm{rpm}$ will decrease the impact strength. In other words, regardless of traverse speed, there is an optimum rotational speed in which the welded specimens could obtain the highest impact strength. As it was mentioned previously, low rotational speeds cause insufficient flow of material in the weld zone, therefore fusion between the weld and base material will be weak. Consequently, the impact strength of welded samples will not be satisfactory. However, if the tool rotational speed increases, stirring of the pin and frictional heat will be increased, and consequently better welds will be obtained in terms of mechanical properties (Rahbarpour et al. 2014). On the other hand, with rotational speed higher than $1570 \mathrm{rpm}$, the materials will be separated by pin, and consequently a weak joint will be obtained.

One interesting result that is obtained from Fig. 6 is the fact that as the traverse speed increases, the optimum rotational speed is almost constant. In other words, regardless of traverse speed, an optimum rotational speed (i.e., $1570 \mathrm{rpm}$ ) can be used for welding polyamide sheets. Nevertheless, if the traverse speed increases, the impact strength of welded samples decreases. This could be because with high traverse speed, the melted material will pour out of the welding area. Additionally, in a high travel speed, high value of temperature could not be created. Therefore, poor mixing of the melted material will happen, and consequently a poor quality weld is obtained.

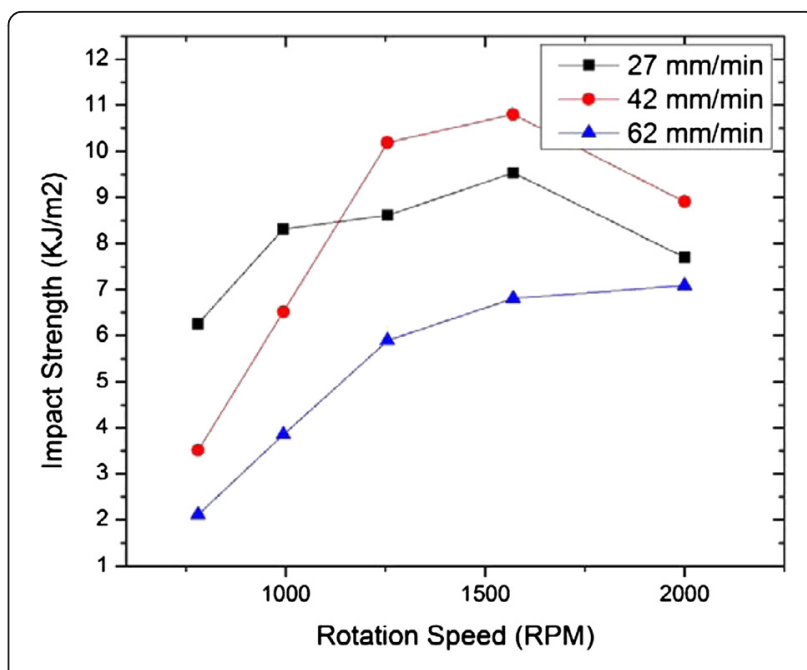

Fig. 6 Impact strength results of the welded samples 


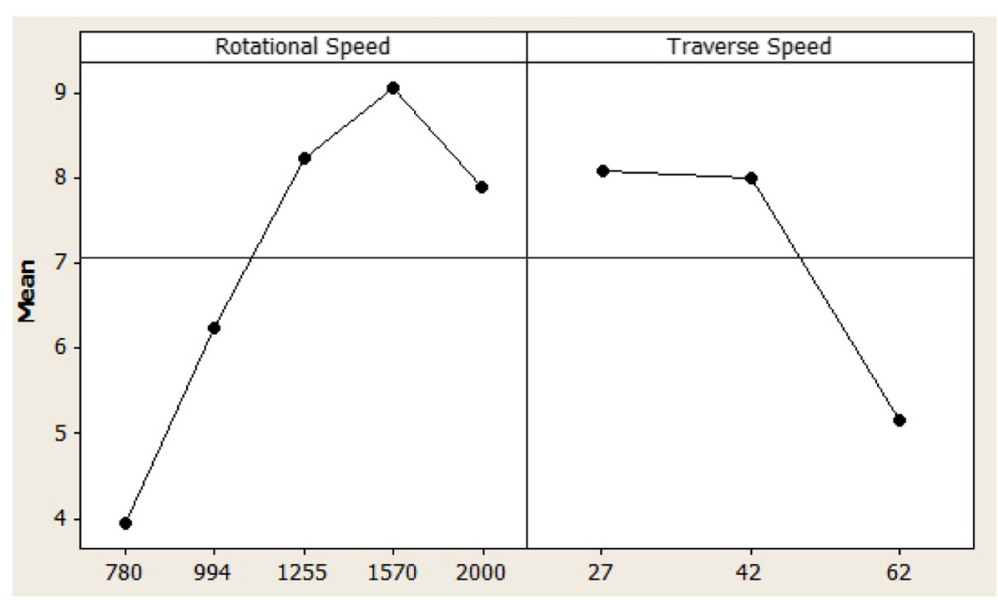

Fig. 7 Main effects of rotational and traverse speed on impact strength

Similar to the results of tensile test, another important result that could be obtained from Table 2 is the condition in which the relative impact strength could be maximized. The maximum relative impact strength of the welded samples is about $29.48 \%$ of the impact strength of base material which is obtained in a specimen welded at $1570 \mathrm{rpm}$ rotational speed and $42 \mathrm{~mm} / \mathrm{min}$ traverse speed. Moreover, the minimum impact strength is about $5.76 \%$ of the base material, which occurred in a sample welded at $780 \mathrm{rpm}$ rotational speed and $62 \mathrm{~mm} / \mathrm{min}$ traverse speed.

Obtained from design of experiments (DOE), the main effect plot of rotational and traverse speed for impact strength is shown in Fig. 7. As it is mentioned in the previous section, the diagrams of this figure also reveal the effect of processing parameters on the mechanical properties of welded samples. As Fig. 7 shows, impact strength increases if the rotational speed increases to $1570 \mathrm{rpm}$, and then further increasing in rotational speed will decrease impact strength of the welded specimens. In addition, impact strength will be decreased when the traverse speed of tool increases.

Another interesting result that could be concluded from Fig. 6 is that in low rotational speed (lower than the optimum rotational speed or $1570 \mathrm{rpm}$ ), impact strength (and also tensile strength in Fig. 4) will decrease with increasing traverse speed. But at high rotational speed (higher than $1570 \mathrm{rpm}$ ), this behavior could not be seen.
In other words, at higher rotational speeds, traverse speed of $42 \mathrm{~mm} / \mathrm{min}$ could be chosen as optimum traverse speed in which the mechanical properties of welded sheets could be maximized.

The ANOVA results of impact strength of welded specimens are shown in Table 4. As results show, all processing parameters have statistically significant effect on tensile strength at the $95 \%$ level of confidence. $F$-values of processing parameters obtained from experimental results are 9.12 and 10.35 for rotational and traverse speeds, respectively. Since these $F$-values are bigger than the concluded $F$-value from statistical calculation (i.e., 3.84 and 4.46, respectively), all processing variables of the present study could be considered as effective parameters on impact strength of welded specimens. It is also concluded that regarding impact strength, rotational speed with the percent effect of 55.98 is the most effective parameter.

\section{Conclusions}

In this paper, friction stir welding process is used to weld polyamide (nylon 66) sheets. As mechanical properties, tensile and impact strength of friction-stir-welded polyamide sheets are studied under varying processing parameters. Results show that welding strength increases when rotational speed increases. However, further increases in rotational speed (higher than $1570 \mathrm{rpm}$ ) will decrease the welding strength. Regarding the traverse speed, it

Table 4 ANOVA table of impact strength

\begin{tabular}{lccccccc}
\hline Source & DOF & SS & MS & $F_{\text {exp }}$ & $F_{0.05}$ & $P$ & Percent effect \\
\hline Rotational speed & 4 & 48.998 & 12.249 & 9.12 & 3.84 & 0.004 & 55.98 \\
Traverse speed & 2 & 27.788 & 13.894 & 10.35 & 4.46 & $\ldots .006$ & 31.75 \\
Error & 8 & 10.741 & 1.343 & $\ldots$ & $\ldots$ & $\ldots$ & $\ldots$ \\
Total & 14 & 87.527 & $\ldots$ & $\ldots$ & $\ldots$ & $\ldots$ & $\ldots$ \\
\hline
\end{tabular}


is concluded that welding strength decreases when the traverse speed increases. The maximum tensile strength of the welded samples was obtained about $8.51 \mathrm{MPa}$. Since the tensile strength of the base material is $15.57 \mathrm{MPa}$, the maximum relative strength of the joint was concluded approximately $55 \%$ in comparison with the base material. Impact strength of the base material was also obtained $36.6 \mathrm{~kJ} / \mathrm{m}^{2}$, while at the optimum conditions, the maximum amount of impact strength was achieved about $10.8 \mathrm{~kJ} / \mathrm{m}^{2}$. It shows that relative impact strength of the best weld was approximately $30 \%$ compared to base material.

\section{Competing interests}

The authors declare that they have no competing interests.

\section{Authors' contributions}

IMH and RKS have performed the welding process of the research work. TA and SH have analyzed the results. SMS have carried out the tensile and impact tests of welded sheets. REL has revised the paper. However all authors read and approved the final manuscript.

\section{Author details}

'Department of Welding, Technical College of Baghdad, Baghdad, Iraq.

${ }^{2}$ Mechanical Engineering Department, Faculty of Engineering, Urmia University, Urmia, Iran. ${ }^{3}$ Faculty of Mechanical Engineering, University of Tabriz, Tabriz, Iran. ${ }^{4}$ Macro Engineering and Technology Inc., Mississauga, Ontario, Canada.

Received: 26 May 2015 Accepted: 19 July 2015

Published online: 01 August 2015

\section{References}

Anna Squeo, E, Bruno, G, Guglielmotti, A, \& Quadrini, F. (2009). Friction stir welding of polyethylene sheets. The Annals Of "Dunarea De Jos" University Of Galati, Fascicle V, Technologies in Machine Building, ISSN: 1221-4566, 241-246.

Arici, A, \& Selale, S. (2007). Effect of tool tilt angle on tensile strength and fracture location of friction stir welding of polyethylene. Science and Technology of Welding \& Joining, 12, 536-539.

Arici, A, \& Sinmaz, T. (2005). Effect of double passes of the tool on friction stir welding of polyethylene. Journal of Material science, 40, 3313-3316.

Aydin, M. (2014). Effect of welding parameters on fracture mode and weld strength friction stir spot welds of polypropylene sheets. Polymer-Plastics Technology and Engineering, 49, 595-601.

Bagheri, A, Azdast, T, \& Doniavi, A. (2013). An experimental study on mechanical properties of friction stir welded ABS sheets. Material and Design, 43, 402-409.

Hoseinpour Dashatan, S, Azdast, T, Rash Ahmadi, S, \& Bagheri, A. (2013). Friction stir spot welding of dissimilar polymethyl methacrylate and acrylonitrile butadiene styrene sheets. Material and Design, 45, 135-141.

International, ASTM. (2010). ASTM standard D638-10, standard test method for tensile properties of plastic. ASTM International. doi:10.1520/D0882-12.

International, ASTM. (2010). ASTM standard D6110-10, standard test method for determining the charpy impact resistance of notched specimens of plastics. ASTM International. doi:10.1520/D6110-10.

Kumar, R, Singh, K, \& Pandey, S. (2012). Process forces and heat input as function of process parameters in AA5083 friction stir welds. Transactions of Nonferrous Metals Society of China, 22, 288-298.

Mendes, N, Loureiro, A, Martins, C, Neto, P, \& Pires, JN. (2014). Morphology and strength of acrylonitrile butadiene styrene welds performed by robotic friction stir welding. Material and Design, 64, 81-90.

Mustafa, KB, Ahmet, IY, \& Memduh, K. (2011). The optimization of welding parameters for friction stir spot welding of high density polyethylene sheets. Materials and Design, 32, 4074-4079.

Panneerselvam, K, \& Lennin, K. (2014). Joining of nylon 6 plate by friction stir welding process using threaded pin profile. Material and Design, 53, 302-307.

Payganeh, GH, Mostafa Arab, NB, Dadgar Asl, Y, Ghasemi, FA, \& Saeidi Boroujeni, M. (2011). Effects of friction stir welding process parameters on appearance and strength of polypropylene composite welds. International Journal of the Physical Sciences, 19, 4595-4601.

Rahbarpour, R, Azdast, T, Rahbarpour, H, \& Mamaghani Shishavan, S. (2014). Feasibility study of the friction stir welding of wood-plastic composites. Science and Technology of Welding and Joining, 19, 673-681.

Rezgui, MA, Ayadi, M, Cherouat, A, Hamrouni, K, Zghal, A, \& Bejaoui, S. (2010). Application of Taguchi approach to optimize friction stir welding parameters of polyethylene. EPJ Web of Conferences, 6, 1-8.

Saeedy, S, \& Besharatigivi, MK. (2010). Experimental application of friction stir welding (FSW) on thermo plastic medium density polyethylene blanks (pp. 841-844). Turkey: ASME 2010 10th Biennial conference on engineering systems design and analysis. ESDA2010-25344.

Saeedy, S, \& Besharati Givi, MK. (2011). Investigation of the effects of critical process parameters of friction stir welding of polyethylene. Proceedings of the Institution of Mechanical Engineers, Part B: Journal of Engineering Manufacture, $225,1305-1310$

Shaikh, A, Bhatt, KD, \& Chaudhary, AB. (2014). Effect of friction stir welding process parameters on polymer weld. International Journal for Technological Research in Engineering, 9, 741-743.

Sorensen, CD, Nelson, TW, Strand, SR, Johns, C, \& Christensen, J. (2001). Joining of thermoplastics with friction stir welding. ANTEC, 1, 1031-1035.

Strand, SR, Carl, DS, \& Tracy, WN. (2003). Effects of friction stir welding on polymer microstructure. ANTEC Conference Proceedings: Brigham Young University.

Szeteiova, K. (2011). Automotive materials plastic in automotive markets today (pp. 27-33). Slovak University of Technology Bratislava: Institute of production technologies, machine technologies and materials, faculty of material science and technology in Trinova.

\section{Submit your manuscript to a SpringerOpen ${ }^{\mathcal{D}}$ journal and benefit from:}

- Convenient online submission

Rigorous peer review

- Immediate publication on acceptance

- Open access: articles freely available online

- High visibility within the field

- Retaining the copyright to your article

Submit your next manuscript at $>$ springeropen.com 